\title{
Design of Controller for Transition of Grid Connected Microgrid to Island Mode
}

\author{
K.Rayudu ${ }^{a}$, A. Jaya laxmi ${ }^{b}$, P. Soumya ${ }^{\mathrm{c}}$, R. Pradeep ${ }^{\mathrm{d}}$, and Tilahun Kochito ${ }^{\mathrm{e}}$.
}

${ }^{a} E E E, B V R I T-N, T e l a n g a n a$, India

в EEE,JNTUHCEH,Telangana, India.

${ }^{c}$ EEE,SRECW, Telangana, India.

D EEE,JNTUHCEH,Telangana,India.

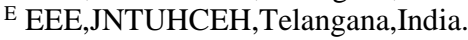

Article History: Received: 11 January 2021; Accepted: 27 February 2021; Published online: 5 April 2021

\begin{abstract}
A microgrid is the combination of Distributed generators that interconnected with the main grid to ensure continuity in supply to the load. The operating system will be in grid-connected and the island mode. This paper presents a mathematical model of hybrid microgrid consisting of PV system, wind power generation using DFIG which are integrated to the utility grid and a PI Controller for controlling the transition from grid-connected mode to island mode and normal operation, each DG inverter sated in constant current control mode to provide preset power to the main grid. When it disconnects from the main grid each DG inverter detects and connect to voltage control mode in the islanding situation. The modeling is performed in MATLAB Simulink and results are discussed out to verify the operation of the proposed system
\end{abstract}

Keywords: Brain Microgrid, Distributed Generations, renewable energy sources, PV system, DFIG, islanding, utility grid.

\section{Introduction}

In the world of rapid progress, electric distribution technology has shown a massive growth in the last few years. The modifications on both the demand and supply side are needed. The higher energy availability and efficiency are desired and the integration of distributed generation as well as good control technologies are required from demand and supply side respectively.

Electric power system is considered as one of the most complex man made network. It requires highly skilled personnel and an efficient technology for its operation and management. Considerable disturbance in electric power system may have a huge impact on other lifeline systems such as water supply and distribution, telecommunication, transportation, national security \& defence (Garikapati, 2020; Bhasa, 2020). Hence, it is required to ensure uninterrupted and highly reliable power supply to all consumers. Further, in case of natural disasters it is not an easy task to tackle the post disaster conditions and restore electric facilities to the remote areas (Balamurugan, 2020). The concept of distributed energy generation proves to be a good solution and curtail the impact of disasters on power system.

. Among the two type of modes, in the grid connected mode the controller has to supply the rated power to the grid and grid signal is used as reference for inverters finally, current control mode is operated in stiff synchronization. In intentional islanding, the controller is designed to supply constant voltage for loads (Kanellos, 2005; Irvin, 2011; ChinnamahammadBhasha, 2020; Deepthi, 2019). PV panel, wind turbine are modeled and a PI controller is used for transition of grid connected to islanding mode.

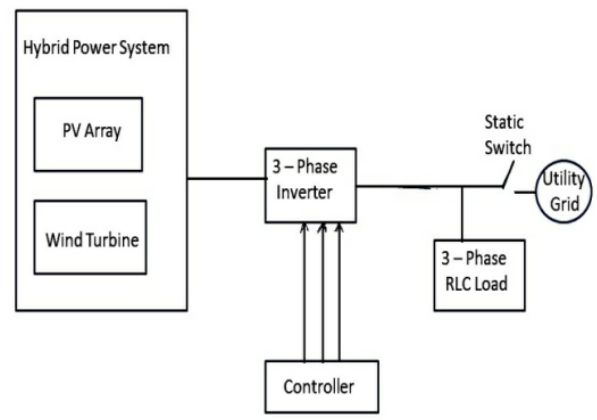

Figure 1. Block diagram of proposed system

\section{Proposed Hybrid System}

\subsection{Photovoltaic System}


In Photovoltaic cell model, both a diode and constant current are in parallel with Rp and all are in series with Rs. Rs and Rp are the internal resistances and inversely related to the leakage current respectively.

If $\mathrm{Rs}$ is zero and $\mathrm{R}_{\mathrm{P}}$ is infinite then photovoltaic cell is ideal. The conversion efficiency of photovoltaic cell is sensitive to small variations in the series resistance but not sensitive to the variations in the shunt resistance. With increase in series resistance, output of photovoltaic cell decreases significantly (Alex Dev, 2013; Amit Singh, 2018; Chinnamahammad Bhasha, 2020; Aroulanandam, 2020)

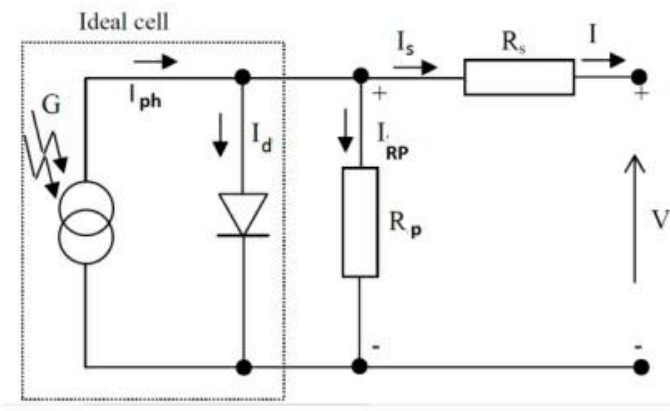

Figure 2. Circuit model for a PV cell

Using Kirchhoff's law

$$
\begin{aligned}
& \mathrm{I}_{\text {Photo }}=\mathrm{I}_{\mathrm{d}}+\mathrm{IR}_{\mathrm{p}}+\mathrm{I} \quad(1) \\
& \text { Ioutput }=\mathrm{I}_{\text {photo }}-\mathrm{I}_{\mathrm{d}}-\mathrm{IR}_{\mathrm{p}}(2) \\
& \quad I=I_{p h}-I_{o}\left[\exp \left(\frac{V+I R_{s}}{V_{T}}\right)-1\right]-\left[\frac{V+I R_{s}}{R_{p}}\right]
\end{aligned}
$$

Where,

Iphoto $=$ Photocurrent of PV

I output = output current (A)

$\mathrm{I}_{\mathrm{O}}=$ Reverse saturation current (A)

$\mathrm{V}=$ output voltage (v)

$\mathrm{R}_{\mathrm{S}}=$ Series resistance $(\Omega)$

$\mathrm{R}_{\mathrm{P}}=$ Parallel resistance $(\Omega)$

$\mathrm{V}_{\mathrm{T}}=$ Thermal voltage $(\mathrm{V})$

Id = Diode current

\subsection{Wind Power System}

The proposed wind turbine consists of a Doubles Fed Induction Generator (DFIG) whose rotor is of squirrel cage type (or) wound rotor type. Stator and rotor windings are star connected to an internal neutral point. It has three inputs, the turbine speed in pu, Generator base speed, the blade pitch angle. The wind speed is applied as torque to the drive train in $\mathrm{pu}$. The rated power of the turbine and synchronous speed of the generator gives the output. The DFIG is one of the common type of generator used to produce electricity in wind turbines. This type of generator maintains the frequency and amplitude of their output voltages (Latchoumi, 2020). Advantages of DFIG are-

a) Operation at variable rotor speed while the frequency and amplitude of the generated voltages remain constant.

b) Optimization of the amount of power generated as a function of the wind available to up the nominal output power of the wind turbine generator. 


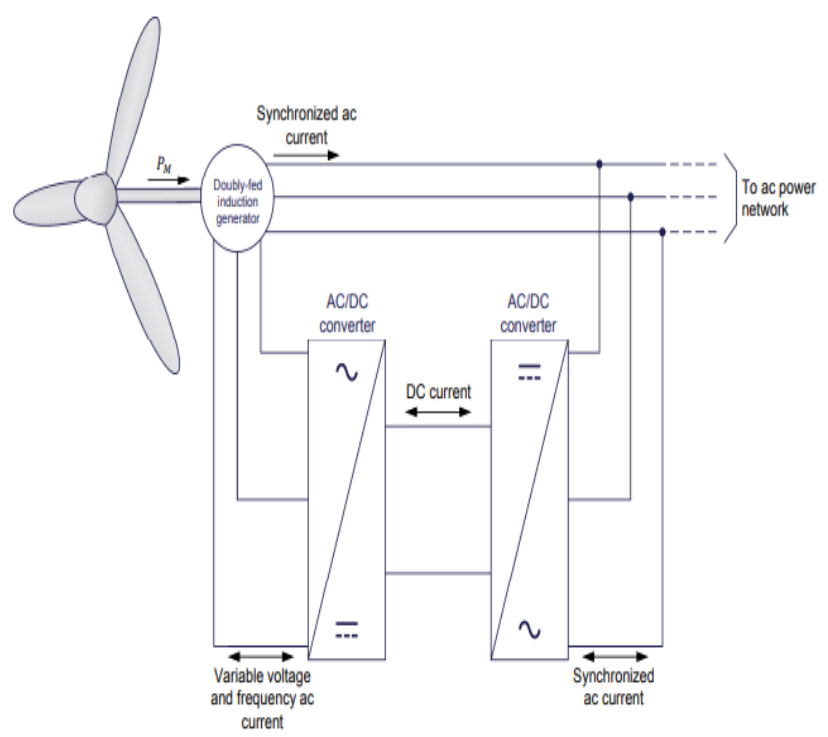

Figure 3. Double-fed induction generator

Wind turbine rotor aerodynamics model is given with $\mathrm{C}_{\mathrm{P}}(\lambda)$ as, (Weidong, 2007).

$\mathrm{Pa}=\mathrm{Wr} . \mathrm{T} \omega=1 / 2 \cdot \rho \cdot \mathrm{A} \cdot \mathrm{Cp}(\lambda, \beta) \cdot \mathrm{V} \omega 3$

Where,

Pa:- aerodynamic power of the wind,

$\mathrm{CP}(\lambda)$ :- coefficient of wind power

( $\lambda$ ) :- tip speed ratio(TSR)

$\rho:-1.25 \mathrm{~kg} / \mathrm{m} 3$, at sea level

A :-rotor swept area,

$\mathrm{V \omega}$ :- wind speed,

Wr :-rotating speed of blade

T $\omega$ :- torque of system.

\subsection{Three Phase PLL}

The DQ - PLL used to detect cutoff system by Clarke's and Park's transformation consists of a PI controller, and an integrator (Esram 2007; Rinu 2012).

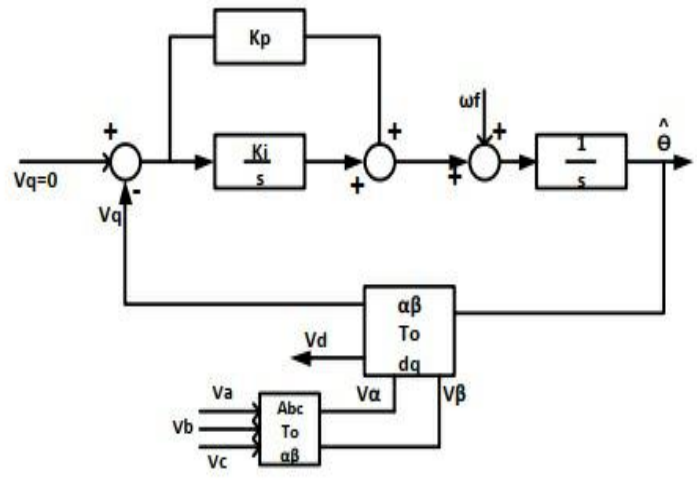

Figure 4. Three phase PLL (Phase Locked Loop) structure 
Phase angle is result of synchronizing rotating reference frame of PLL and the utility voltage vector. PLL is locked by phase angle of the utility voltage vector that achieved by setting the $\mathrm{d}$ - axis reference voltage to zero and determines instantaneous frequency as well as amplitude of voltage vector.

The current is control operated by controlling Id and Iq by generating reference voltages with respect to $\mathrm{d}$ axis and q- axis. The voltage control mode is operated by controlling $\mathrm{Vd}$ and $\mathrm{Vq}$, with respect to reference currents of direct-axis and quadrature- axis (Anila Antony, 2016; Senthamizh Selvi, 2019)

\subsection{Pulse Width Modulation}

PWM is a digital signal that was generated with modulation technique used to encode pulsing signal. This method is used to control transmission of information that aims at the control of power supply to devices. PWM technique is adopted in this model to control power supply to inverter switches and to implement algorithm of MPPT. There are four types of PWM techniques which are mentioned as follows:

- Single PWM

- Multi PWM

- Carrier Wave PWM

- Space Vector pulse (SVPWM)

Sinusoidal PWM is used in this case, sinusoidal wave is the power signal and triangular wave is the carrier signal. Whenever the amplitude of power signal exceeds that of carrier signal, HIGH pulses are generated which are transmitted to the gates of inverter switches. Otherwise, LOW pulses are transmitted to the gates of inverter switches. Fig. 4 shows the SPWM waveforms.

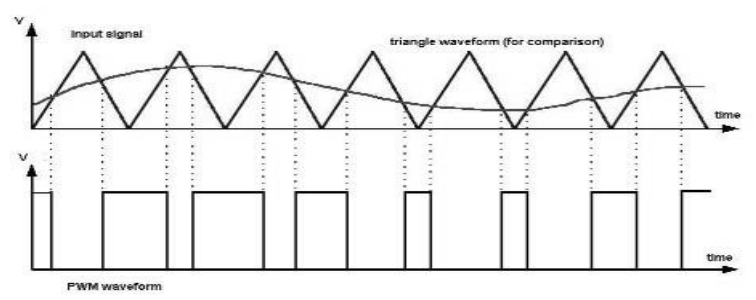

Figure 4. SPWM Waveforms

Due to the modulation of voltage in every sampling interval, SPWM has better dynamic performance than PWM. The modulation pulses are arranged in sinusoidal form

\subsection{Incremental Conductance Method}

This algorithm works with observation and the subsequent equation sets at the MPPT of the system.

$\Delta \mathrm{I} / \Delta \mathrm{V}=-\mathrm{I} / \mathrm{V}$, at Maximum power point

$\Delta \mathrm{I} / \Delta \mathrm{V}>-\mathrm{I} / \mathrm{V}$, left of maximum power point

$\Delta \mathrm{I} / \Delta \mathrm{V}<-\mathrm{I} / \mathrm{V}$, right of maximum power point

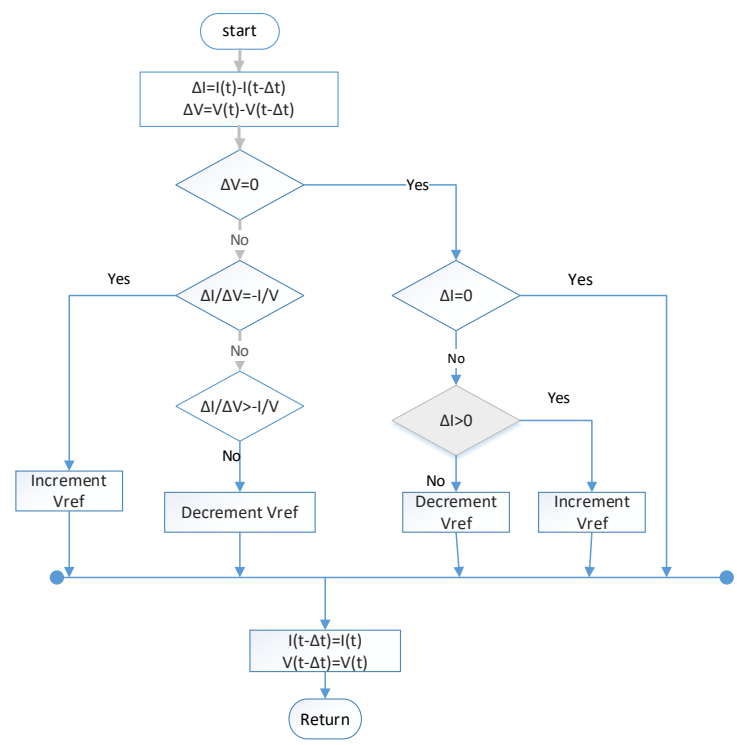


Figure 6. Flowchart of Incremental Conductance maximum power point

\subsection{Intentional Islanding}

If the system voltage (v) and frequency $(\mathrm{Hz})$ are in pre-set ranges, then it will operate in grid-connected mode. Otherwise, undergoes a transition to islanding mode.

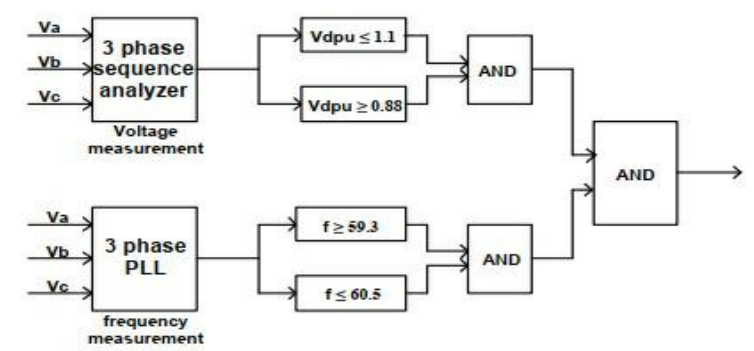

\subsection{Resynchronization Algorithm}

Figure 7. Intentional islanding algorithm

Although this paper deals with transition of grid connected microgrid to islanded mode, an algorithm for grid resynchronization is also proposed. The phase angle between islanded and utility grid are necessary to be same for reconnection of system and resynchronization is done with phase difference on both islanded and utility grid (Jayanthiladevi, 2018; Sampathkumar, 2020; Sampathkumar, 2020)

Assuming $\theta$ is phase difference between inverter voltage and utility grid then,

$$
\begin{aligned}
& \theta=\llcorner\mathrm{VG}-\llcorner\mathrm{VI} \\
& \mathrm{K}=3 / 2 *[\cos (\theta)] \\
& \mathrm{g}=3 / 4 *[-\cos (\theta)+\sqrt{ } 3 \cdot \sin (\theta)] \\
& \sin (\theta)=\left(\frac{4}{3} \mathrm{~g}+\frac{2}{3} \mathrm{k}\right) / \sqrt{ } 3
\end{aligned}
$$

Where $\sin (\theta)$ is determined from grid and inverter voltages and when $\operatorname{Sin}(\theta)$ is zero the system will be in synchronism.

\section{Simulink Model Description}

The transition of grid connected to islanded mode has been implemented with this model. Table 1 below represents the design parameters used in this model. Fig. 8 shows the hybrid PV and wind model. Fig. 9 shows the power circuit model and Fig. 10 shows control circuit model respectively.

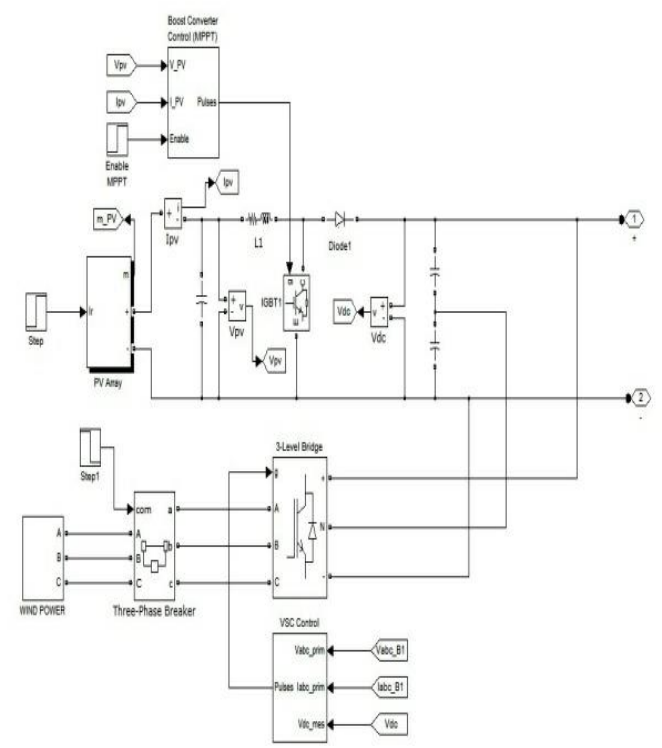

Figure 8. Hybrid PV and Wind model 
Table 1. Design Parameters of The Model

\begin{tabular}{|c|c|c|}
\hline Description & Symbol & Value \\
\hline L filter & $\mathrm{Lf}_{\mathrm{f}}$ & $1 \mathrm{mH}$ \\
\hline $\mathrm{C}$ filter & $\mathrm{C}_{\mathrm{f}}$ & $31 \mu \mathrm{F}$ \\
\hline L filter & $\mathrm{L}_{\mathrm{f}}$ & $0.5 \mathrm{mH}$ \\
\hline load capacitance & $\mathrm{C}_{\mathrm{L}}$ & $1.535 \mathrm{mF}$ \\
\hline load resistance & $\mathrm{R}_{\mathrm{L}}$ & $4.33 \Omega$ \\
\hline load inductance & $\mathrm{LL}_{\mathrm{L}}$ & $4.585 \mathrm{mH}$ \\
\hline Grid resistance & $R_{\text {grid }}$ & $0.1 \Omega$ \\
\hline Grid inductance & Lgrid & $0.1 \mathrm{mH}$ \\
\hline Temperature & $\mathrm{T}$ & $28^{\circ} \mathrm{C}$ \\
\hline Power rating of $\mathrm{PV}$ & $\mathrm{P}_{\text {solar }}$ & $1 \mathrm{~kW}$ \\
\hline Power rating of DFIG & PDFIG & $1 \mathrm{~kW}$ \\
\hline System frequency & $\mathrm{F}$ & $60 \mathrm{~Hz}$ \\
\hline Switching frequency & $\mathrm{f}_{\mathrm{s}}$ & $1 \mathrm{kHz}$ \\
\hline output phase voltage & $\mathrm{V}_{0}$ & $120 \mathrm{~V}$ \\
\hline
\end{tabular}

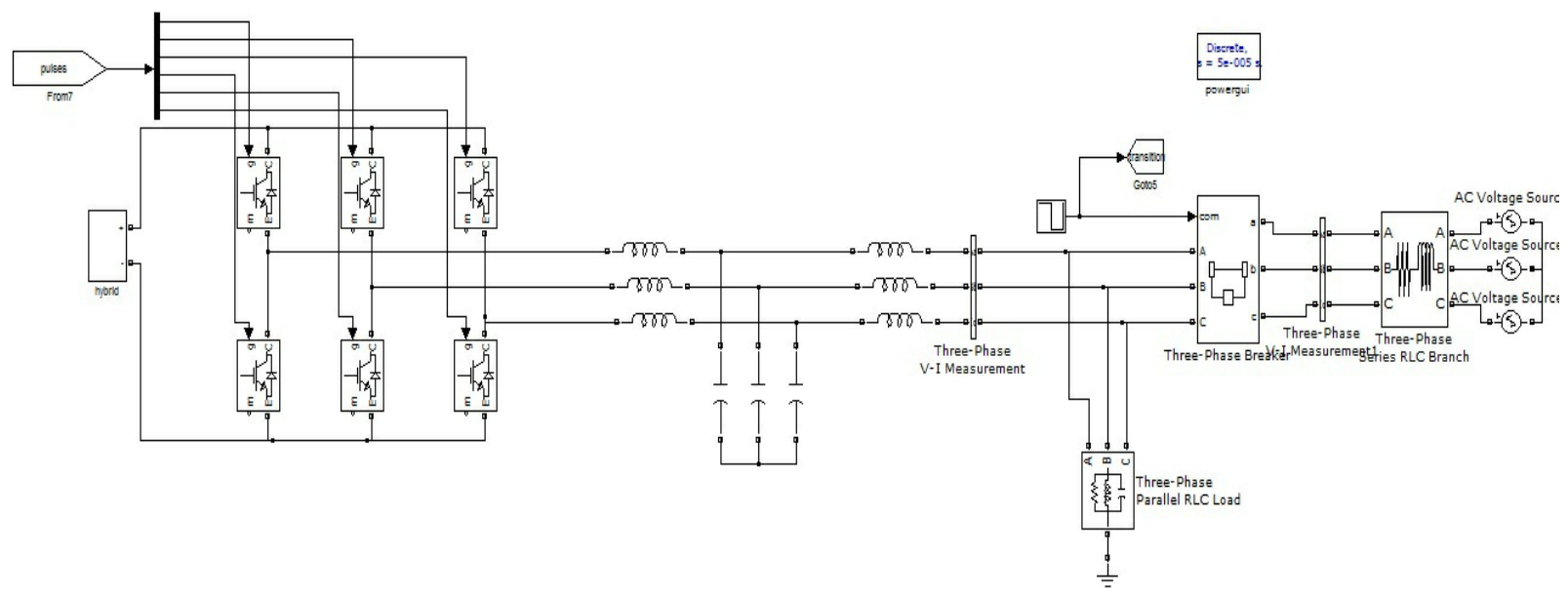

Figure 9. Power circuit model 


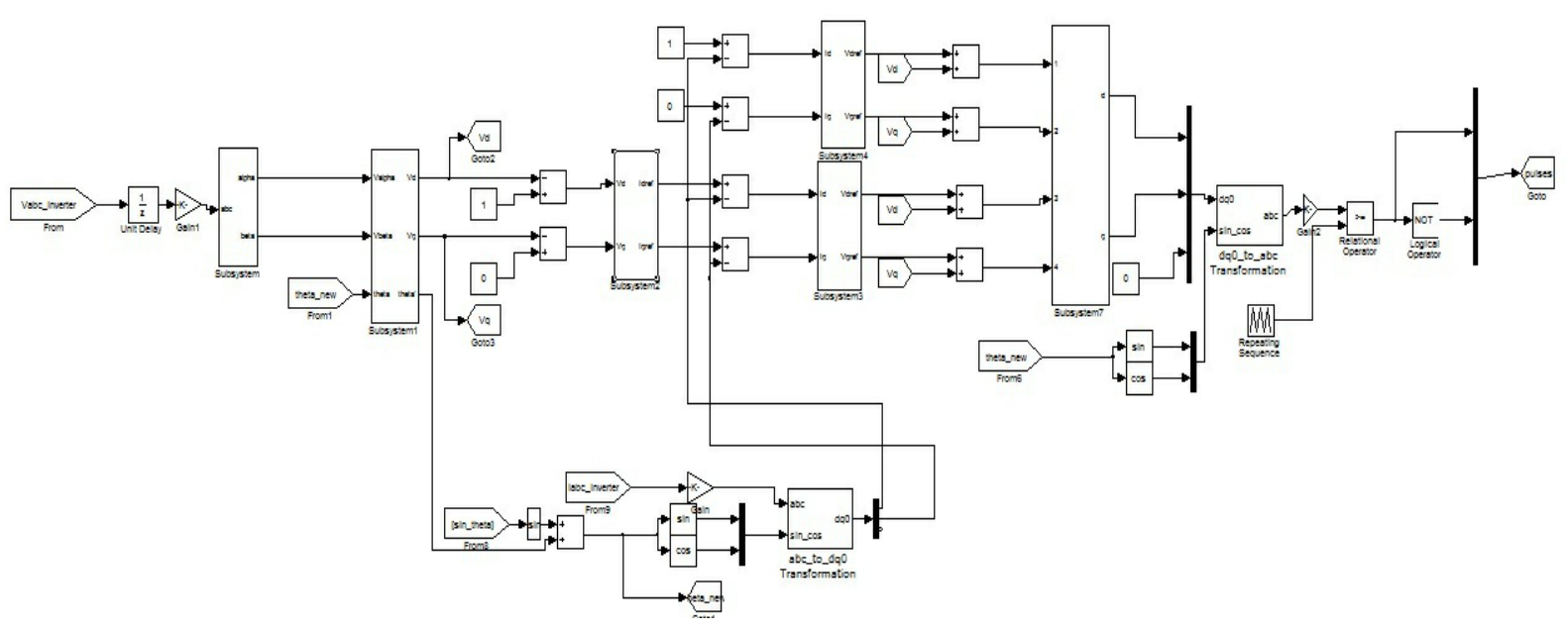

Figure 10. Control circuit model

Fig.9 shows power circuit model which consists of photovoltaic source, Wind power source using DFIG, three phase inverter and utility grid. Incremental conductance method of MPPT has been implemented to maximize the power output from PV source. Control circuit consists of abc to dq conversion system, three phase PLL, PI controller and resynchronization controller.

\section{Simulation Results}

The simulation is done using MATLAB and performance of hybrid power system in grid connected and islanding modes have been studied. Initially all the sources are in synchronism. The system operates in current control mode. A disturbance is created at time $0.3 \mathrm{sec}$ by sending a trip signal to circuit breaker connected to utility grid. Three phase PLL and phase sequence analyzer detects the islanding condition and hence the controller enables the system to operate in voltage control mode. Hence, system operates in grid connected mode till time $0.3 \mathrm{sec}$ and then gets transited to island mode.

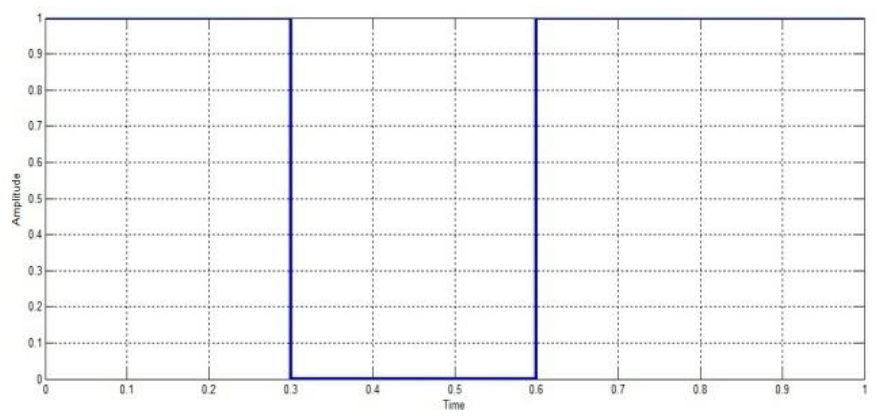

Figure 11. Transition to island mode

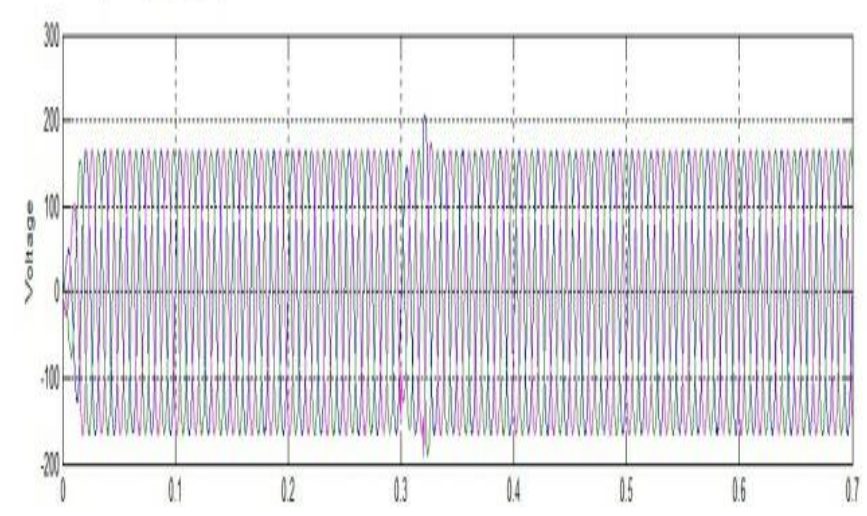

Figure 12. Inverter voltage 


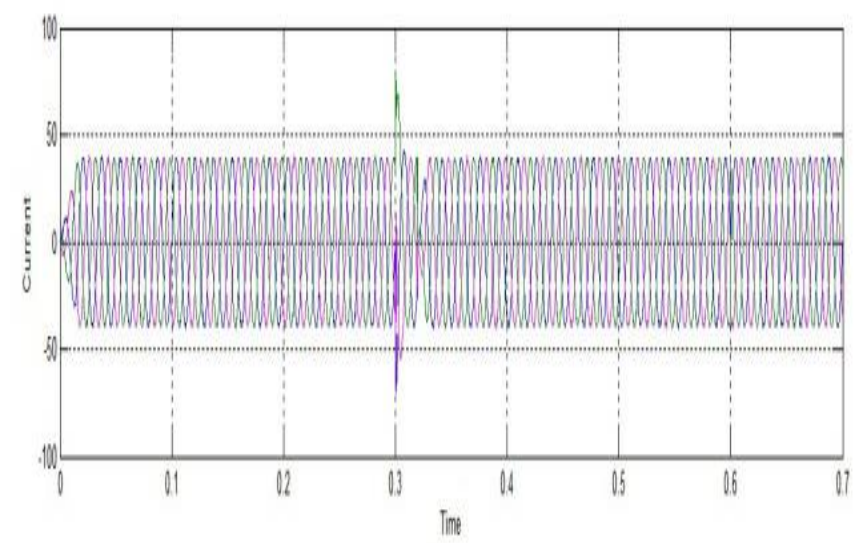

Figure 13. Inverter voltage

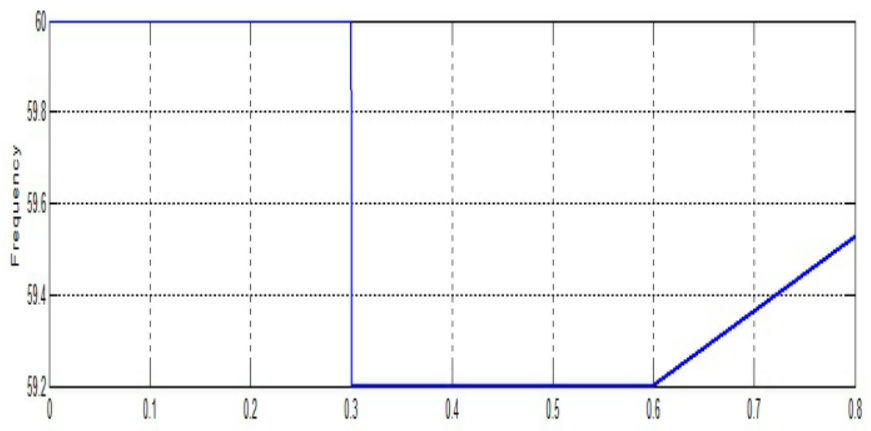

Figure 14. Variation of grid parameters during islanding Frequency

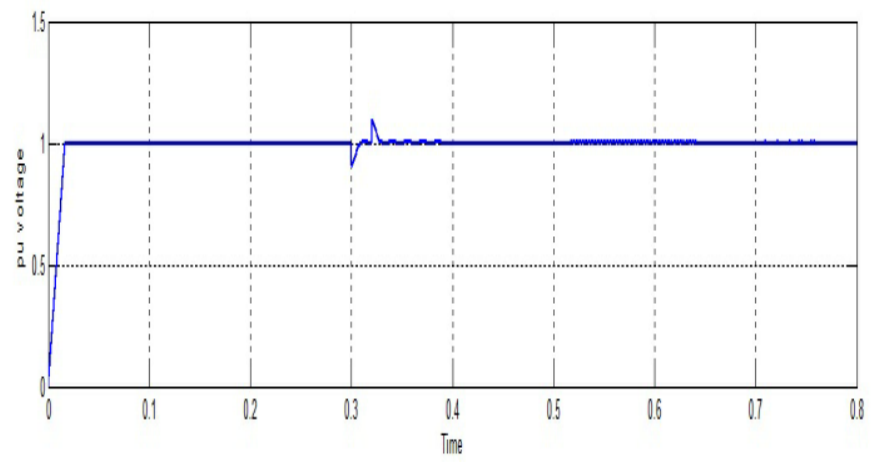

Figure 15. Variation of grid parameters during islanding Voltage in pu

At time $0.6 \mathrm{sec}$ grid is reconnected without resynchronization controller, there is a voltage spike at this instant. with resynchronization controller, voltage spike can be eliminated. Following figures show results obtained after simulation of the proposed model in MATLAB. 


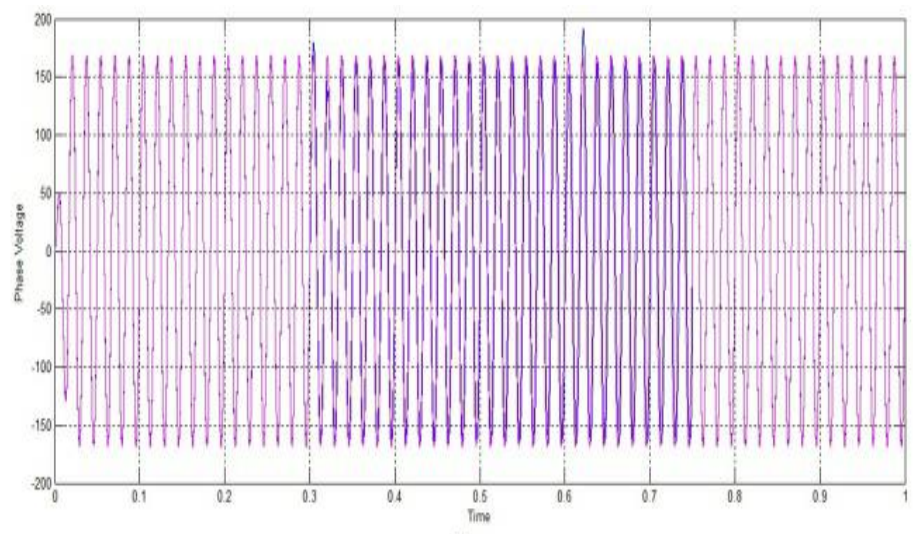

Figure 16. Load Voltage without reclosure algorithm

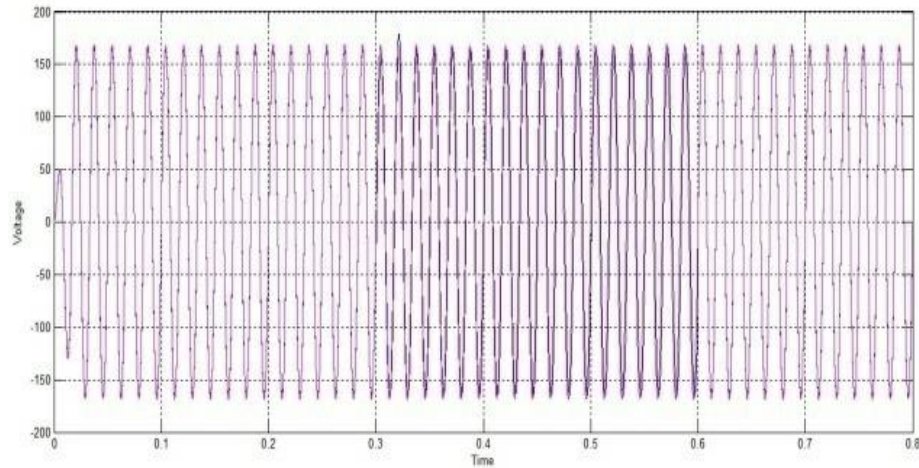

Figure 17. Load Voltage with reclosure algorithm

\section{Conclusion}

The developed control technique for both grid and intentional islanding mode operate with PI Controllers. Intentional islanding detection algorithms are effective for proposed operations and reconnect the micro sources to synchronize with the utility grid automatically. The current and voltage control techniques are developed for grid connected and intentional islanding mode operations using PI Controllers. An intentional islanding detection algorithm is responsible for switching between current control and voltage control which is developed using logical operations and proved to be effective. There connection algorithm coupled with synchronization controller enabled the micro sources to synchronize with the utility grid by themselves during grid reconnection.

When DC Source and utility grid are isolated, there will be no power transfer to load, where as in hybrid system, when two sources are isolated, the third source will supply the power to the load. Hence, reliability of power supply can be improved with hybrid power system. The performance of the microgrid with proposed controllers and algorithms have been analysed by conducting simulation on dynamic model using SIMULINK.

\section{References}

1. Alex Dev, Berlin Jeyapradha, S. (2013) Modeling and simulation of PV module in MATLAB," Proceedings of International conference on Applied Mathematics and theoretical Computer science.

2. Anila Antony, Devika Menon. (2016) Islanding detection technique of distribution generation system," IEEE International Conference on Circuit, Power and Computing Technologies (ICCPCT).

3. Amit Singh, R.S., Bhatia, Saurabh Chanana. (2018) An Anti-Islanding Technique for Grid-Connected DG and multi DG System," International Conference on Emerging Trends and Innovations in Engineering and Technological Research (ICETIETR) 2018.

4. Aroulanandam VV, Latchoumi TP, Balamurugan K, Yookesh TL. (2020) Improving the Energy Efficiency in Mobile Ad-Hoc Network Using Learning-Based Routing, Revue d'Intelligence Artificielle, Vol 34(3), pp. 337-343, 2020

5. Balamurugan K. (2020) Metrological changes in surface profile, chip, and temperature on end milling of M2HSS die steel. International Journal of Machining and Machinability of Materials, 22(6):pp. 443-453.

6. Bhasha, A.C., Balamurugan, K. (2020) End mill studies on Al6061 hybrid composite prepared by ultrasonic-assisted stir casting. Multiscale and Multidiscip. Model. Exp. and Design, https://doi.org/10.1007/s41939-020-00083-1

7. ChinnamahammadBhasha, A., Balamurugan, K. (2020) Studies on Al6061nanohybrid Composites Reinforced with $\mathrm{SiO} 2 / 3 x \%$ of TiC -a Agro-Waste. Silico,. https://doi.org/10.1007/s12633-020-00758-x 
8. Chinnamahammad Bhasha and Balamurugan K, (2020) Multi-objective optimization of high-speed end milling on Al6061/ 3\% RHA/ 6\% TiC reinforced hybrid composite using Taguchi coupled GRA, International Conference on Computational Intelligence for Smart Power System and Sustainable Energy (CISPSSE), Keonjhar, India, 2020, pp. 1-6, doi: 10.1109/CISPSSE49931.2020.9212295.

9. Deepthi T, and Balamurugan K. (2019) Effect of Yttrium (20\%) doping on mechanical properties of rare earth nano lanthanum phosphate (LaPO4) synthesized by aqueous sol-gel process. Ceramics International. 45(15), pp.18229-18235.

10. Esram, T., Chapman, P. L. (2007) Comparison of Photovoltaic Array Maximum Power Point Tracking Techniques," Energy Conversion, IEEE Transactions on, 22, pp. 439-449.

11. Irvin J. Balaguer, Qinlei Shuitao Yang, Uthane Suppati. (2011) Control of grid connected and intentional islanding operations for distributed power generation,"” IEEE Journal, 58 (1).

12. Garikapati P, Balamurugan K, Latchoumi TP, Malkapuram R. (2020) A Cluster-Profile Comparative Study on Machining AlSi 7/63\% of SiC Hybrid Composite Using Agglomerative Hierarchical Clustering and K-Means. Silicon. https://doi.org/10.1007/s12633-020-00447-9

13. Jayanthiladevi, A., Murugan, S., \& Manivel, K. (2018). Text, images, and video analytics for fog computing. In Handbook of Research on Cloud and Fog Computing Infrastructures for Data Science (pp. 390-410).

14. Kanellos, F.D., Tsouchnikas, A.I., Hatziargyriou, N.D. (2005) Micro-Grid simulation during grid connected and islanded modes of operation, "International conference on power system transients, Paper No. IPST05 113.

15. Latchoumi TP, Reddy MS, Balamurugan K. (2020) Applied Machine Learning Predictive Analytics to SQL Injection Attack Detection and Prevention. European Journal of Molecular \& Clinical Medicine.;7(02), pp. 3543-3553.

16. Rinu J Vijayan, Subhramanyam Ch. (2012) Dynamic Modelling of Microgrid for Grid Connected and Intentional Islanding Operation,"International Conference on Advances in Power Conversion and Energy Technologies (APCET).

17. Senthamizh Selvi, R., Sivakumar, D., Siva Sowmiya, S., Ramya, S., Kanaga Suba Raja ,S. (2019) Face Recognition Using Haar - Cascade Classifier for Criminal Identification', International Journal of Recent Technology and Engineering, ISSN: 2277-3878, 7, 6S5, pp. 1871-1876.

18. Sampathkumar, A., Murugan, S., Ahmed, A., Elngar, Lalit Garg, Kanmani, R., Christy Jeba Malar, A. (2020) A Novel Scheme for an IoT-Based Weather Monitoring System Using a Wireless Sensor Network." In Integration of WSN and IoT for Smart Cities :181-191.

19. Sampathkumar, A., Maheswar, R., Pon Harshavardhanan, Murugan, S., Jayarajan, P., Sivasankaran, V. (2020) Majority Voting based Hybrid Ensemble Classification Approach for Predicting Parking Availability in Smart City based on IoT." In 2020 11th International Conference on Computing, Communication and Networking Technologies (ICCCNT) : 1-8.

20. Weidong, X., Dunford, W. G., Palmer, P. R., Capel, A. (2007) Regulation of Photovoltaic Voltage," IEEE Transactions on Industrial Electronics, vol. 54, pp. 1365-1374. 